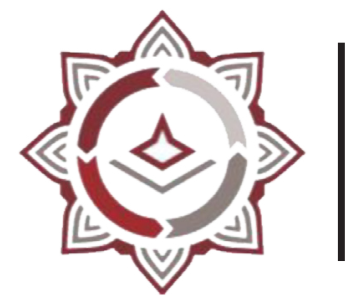

BISNIS: Jurnal Bisnis dan Manajemen Islam

P-ISSN: 2442-3718, E-ISSN: 2477-5533

Volume 9, Nomor 1, Juni 2021 (PP : 33-52)

https://journal.iainkudus.ac.id/index.php/Bisnis/index

http://dx.doi.org/10.21043/bisnis.v9i1.11461

\title{
Pengaruh Etika Bisnis Islam dan Bauran Pemasaran Terhadap Loyalitas Nasabah dengan Keputusan Menjadi Nasabah Sebagai Variabel Intervening (Studi pada BPD Jateng Syariah, BRI Syariah dan Bank Muamalat) di Kota Semarang
}

\author{
Salam $^{1}$, Habibah ${ }^{2}$ \\ IAIN Surakarta' ${ }^{1}$ IAIN Kudus ${ }^{2}$ \\ Salamabdus2989@gmail.com ${ }^{1}$,habibah@iainkudus.ac.id ${ }^{2}$
}

\begin{abstract}
These study aims to determinew the system from the application of Marketing Mix and Islamic Business Ethicss there is Customer loyalty in Islamic Banking (BRI Syariah, Bank Jateng Syariah and Bank Muamalat) in Semarang City. By using the variables of Marketing Mix and Islamic Business Ethics as Exogenous Variables and Customer Loyalty as Endogenous Variables, besides that, intervening variables are also used to seasure the mediating effect of exogenous to endogenousfactors. Sampling using purposive sampling. The data used is primary data from 3 Islamic Banking customers who are 100 respondents. The results of the study explain that first, the Marketing Mix affects the decision to becomea customer. Second, Islamic Business Ethics influences the decision to became a customer. Third, Marketing Mix has an effect on Customer Loyalty. Fourth, Islamic Business Ethics has no effect on Customer Loyalty. Fifth, the decision to become a customer affects customer loyalty. Sixth, the decision to become a customer is able to mediate between marketing and customer loyalty. Seventh, the decision to become a customer is unable to mediate Islamic Business Ethics on Customer Loyalty.
\end{abstract}

Keywords: Marketing Mix, Islamic Business Ethics,Sharia Banking, Loyalty.

\begin{abstract}
Abstrak
Penelitian ini bertujuan untuk mengetahui sistem dari penerapan Marketing Mix dan Etika Bisnis Islam terdapat Loyalitas Nasabah pada Bank Syariah (BRI Syariah, Bank Jateng Syariah dan Bank Muamalat) di Kota Semarang. Dengan menggunakan varibel Marketing Mix dan Etika Bisnis Islam sebagai Variabel Eksogen dan Loyalitas Nasabah sebagai variabel Endogen, selain itu juga digunakan variabel intervening untuk mengukur pengaruh mediasi
\end{abstract}


dari faktor eksogen ke endogen. Pengambilan sampel menggunakan purposive sampling. Data yang digunakan adalah data primer yang diperoleh dari 3 nasabah bank syariah, dengan total responden sejumlah 100 responden. Hasil penelitian menjelaskan bahwa pertama, Marketing Mix berpengaruh terhadap keputusan menjadi nasabah. Kedua, Etika Bisnis Islam berpengaruh terhadap keputusan menjadi nasabah. Ketiga, Marketing Mix berpengaruh terhadap Loyalitas Nasabah, Keempat, Etika Bisnis Islam tidak berpengaruh terhadap Loyalitas Nasabah. Kelima, Keputusan Menjadi Nasabah berpengaruh terhadap Loyalitas Nasabah. Keenam, Keputusan Menjadi Nasabah mampu memediasi antara Marketing terhadap Loyalitas Nasabah. Ketujuh, Keputusan Menjadi Nasabah tidak mampu memediasi Etika Bisnis Islam terhadap Loyalitas Nasabah.

Kata Kunci: Marketing Mix, Etika Bisnis Islam, Bank Syariah, Loyalitas

\section{PENDAHULUAN}

Lahirnya bank Mualamat sebagai bank pelopor bank syariah memberikan respon positif terhadap bank konvensional yang ikut melahirkan bank syariah. Tercatat tahun 2014 dan 2015 ada 12 bank umum syariah dan pada tahun 2017 naik menjadi 13 bank umum syariah dengan total aset 288.027 (miliar rupiah). Tahun 2014 dan 2015 ada 22 unit usaha syariah, namun terjadi penurunan di tahun 2016 dan 2017 menjadi 21 unit usaha syariah dengan total aset 136.154 (miliar rupiah) dan dari tahun 2014 ada 163 BPR Syariah pada tahun 2017 meningkat 167 BPR syariah dengan aset 167 miliar. (www.ojk.go.id, 2017)

Bauran pemasaran atau Marketing Mix adalah gabungan variabel atau cara terpenting dari sistem pemasaran, variabel pada Marketing Mix (bauran pemasaran) bisa digunakan oleh perusahaan secara optimal untuk menarik atau mempengaruhi calon nasabah atau konsumen.

Menurut Philip Kotler, Bauran Pemasaran yaitu suatau cara pemasaran yang digunakan perusahaan untuk dapat mencapai suatu tujuan pemasaran di titik pasar sasaran. Selain Marketing Mix yang menjadi penopang keberhasilan suatu perusahaan, juga perlu ditopang dengan sikap yang baik yaitu dengan menerapkan etika, yaitu Etika Bisnis Islam. Agama islam memperintahkan umatnya mendapatkan rezeki yang halal. Tidak hanya mengumpulkan harta benda, tapi juga dengan cara atau etika yang Islami.

Tiga (3) bank syariah yang akan dijadikan obyek penelitian, yaitu Bank BRI Syariah (Sekaeang BSI), Bank Muamalat dan Bank Jateng Syariah. Pemilihan obyek 
ini karena BRI Syariah mempunyai aset yang tinggi pada tahun 2014 dan 2015 dan mewakili bank syariah milik negara. Bank Muamalat dipilih karena merupakan bank syariah yang pertama lahir tapi mengalami penurunan aset pada tahun 2014 dan 2015 dan mewakili bank swasta. Bank Jateng Syariah dipilih sebagai bank syariah yang mewakili pemerintah daerah Provinsi Jawa Tengah.

Selain Marketing Mix atau bauran pemasaran yang mampu meningkatkan penjualan perusahaan ada faktor lain yang juga mampu untuk diperdalam untuk menarik konsumen/nasabah menggunakan atau membeli jasa/produk suatu perusahaan yaitu Etika Bisnis Islam.

Etika bisnis pada dasarnya bukanlah strategi baru dan bukan kajian baru, karena sejak abad ke 18 sampai sekarang kolaborasi etika dan bisnis sudah banyak didiskusikan. Persoalan etika bisnis muncul jika terjadi suatu konflik tanggungjawab kebutuhan atau kebingungan memilih yang benar dan salah, yang salah dengan yang lebih salah atau mempertimbangkan sesuatu yang lebih kompleks yang diakibatkan oleh aktivitas bisnis.

Penelitian yang dilakukan Khafiatul Hasanah menjelaskan bahwa, adanya pengaruh yang dominan dari variabel Etis (akhlakiyah) selain itu juga marketing syariah mampu diterapkan untuk meningkatkan kepercayaan nasabah dan melakukan bisnis islami secara istiqamah. (Khafiatul Hasanah, 2016:19). Teuku Meldi Kusuma dalam penelitiannya menyimpulkan bahwa informasi yang diberikan melalui media mempunyai kekuatan yang besar untuk membentuk perilaku, image, pandangan dan tindakan dari masyarakat luas, dengan menggunakan prinsip tauhid, keadilan dan amanah ini perusahaan mampu mendapatkan keberkahan melalui perniagaan, inilah yang menjadi temuan terbaru dari penelitian ini. (Teuku Meldi Kusuma,2012:80).

Penelitian Rauly Sijabat, untuk membangun sebuah kinerja pemasaran membutuhkan kapabilitas jaringan usaha yang sangat kuat. Dengan melalui inovasi dan kreativitas diupayakan menggunakan program pemasaran. (Rauly Sijabat, 2017:38)

Berdasarkan latar belakang penelitian yang dijelaskan, penelitian ini bertujuan untuk mengetahui pengaruh Marketing Mix terhadap keputusan menjadi Nasabah Bank Syariah di Kota Semarang. Mengetahui pengaruh Etika Bisnis Islam terhadap 
Keputusan Menjadi Nasabah pada Bank Syariah di Kota Semarang. Mengetahui pengaruh Marketing Mix terhadap Loyalitas Nasabah Bank Syariah di Kota Semarang. Mengetahui pengaruh Etika Bisnis Islam terhadap Loyalitas Nasabah pada Bank Syariah di Kota Semarang. Mengetahui pengaruh Keputusan Menjadi Nasabah Bank Syariah terhadap Loyalitas Nasabah pada Bank Syariah di Kota Semarang.

Selain itu juga mengetahui Keputusan Menjadi Nasabah dapat menjadi mediasi Marketing Mix dengan Loyalitas Nasabah pada Bank Syariah di Kota Semarang. Tujuan terakhir dari penelitian ini bermaksud untuk mengetahui Keputusan Menjadi Nasabah dapat menjadi mediasi antara Etika Bisnis Islam dengan Loyalitas Nasabah pada Bank Syariah di Kota Semarang.

\section{KAJIAN LITERATUR}

\section{Pemasaran}

Pemasaran adalah kegiatan - kegiatan pokok yang bisa dilakukan oleh para pengusaha terhadap usaha untuk mempertahankan hidupnya. Sukses tidaknya perusahaan mencapai tujuannya dipengahuri oleh sumber daya manusia perusahaan dalam mengelola fungsi-fungsi pemasaran sebagai ujung tombak perusahaan.

Pengertian pemasaran menurut William J Stanton Michael J Etzel Bruch J Walker adalah "marketing is a total system designed to plan, price, promote and distribute wat satisfying products to target market to achieve organization objective". ( H. Djaslim Saladin, 1994:1)

Menurut Philip Kotler pemasaran adalah "marketing is a social and managerial process by which individuals and groups obtain what they need and what through creating, offering, and exchanging products of values of with other" ( H. Djaslim Saladin, 1994:1)

Tujuan pemasaran yaitu agar konsumen yang mempunyai potensi tahu keseluruhan produk yang dihasilkan dan perusahaan mampu menghadirkan semua kebutuhan konsumen dan produk yang dihasilkan. Kegiatan pemasaran itu meliputi bermacam-macam kegiatan, mulai dari keterangan terhadap produk, desain, promosi iklan, komunikasi kepada konsumen sampai pengiriman produk ketika sampai pada konsumen. (Sudaryono, 2017:268). 


\section{Marketing Mix}

Marketing Mix adalah gabungan yang terdiri dari strategi produk, penentuan harga, distribusi dan promosi untuk digunakan membuat bermacam-macam produk.

\section{a. Produk}

Produk adalah sifat komplek baik yang bisa diraba atau tidak bisa diraba, begitu juga bungkus, warna, harga, prestise perusahaan dan pengecer, layanan perusahaan dan pengecer yang diterima oleh pembeli untuk memuaskan kebutuhannya. (Basu Swastha, 1994:78)

Menurut Philip Kotler, produk adalah segala hal yang mampu untuk ditawarkan ke public atau pasar untuk diperhatikan, dipunyai, digunakan atau dikonsumsikan, sehingga mampu memuaskan kebutuhan.

Pada dasarnya semua produk secara hirarki ada sangkut pautnya dengan produk tertentu. Hirarki produk bisa dimulai dari kebutuhan dari sampai dengan tipe produk yang akan memuaskan kebutuhan tersebut. Identifikasi tujuh tingkat hirarki produk yaitu kelompok kebutuhan artinya kebutuhan kelompok merupakan kebutuhan inti yang nantinya akan membentuk kelompok produk. Kedua, Kelompok produk, artinya semua produk kelas bisa memuaskan kebutuhan inti dengan tingkat efektivitas yang kurang lebih memadai. (Philip Kotler dan Kevin Lane Keller, 1993:58)

Ketiga, kelas produk, artinya sekelompok produk dalam kelompok produk yang sudah dianggap mampu memiliki hubungan fungsional tertentu. Keempat, lini produk artinya sesuatu produk di dalam kelas produk yang mempunyai berhubungan erat, karena fungsinya yang sama atau karena dijual pada kelompok konsumen yang sama atau karena dipasarkan melalui saluran distribusi yang sama atau karena harganya berada dalam skala yang sama. (Philip Kotler dan Kevin Lane Keller, 1993:58)

Kelima, tipe produk, artinya barang yang berada pada lini produk dan mempunyai wujud tertentu dari banyak kemungkinan bentuk. Merek, artinya nama yang dapat dihubungkan dengan satu hal atau lebih barang atau hal yang melihat dalam lini produk dan digunakan untuk mengenal sumber atau ciri barang tersebut. Ketujuh, jenis produk artinya sesuatu 
yang khusus untuk suatu merek atau lini produk yang dapat dibedakan dengan ukuran, harga penampilan atau atribut yang lain. (Philip ${ }^{\text {Kotler }}$ dan Kevin Lane Keller, 1993:58)

Ada beberapa tahapan yang ditempuh di dalam membuat produk antara lain :

a. Perencanaan produk

Yang mencakup segala hal kegiatan produsen untuk menentukan susunan produk line-nya.

b. Pengembangan Produk

Yang mencakup aktifitas teknis terkait penelitian, pembuatan dan permodelan produk.

c. Persiapan Sebelum Penjualan

Yang mencakup segala hal perencanaan dari produsen ke penyalur untuk menyesuaikan produknya sesuai permintaan pasar. (Basu Swastha, 1994:79).

\section{b. Harga}

Harga adalah jumlah uang yang akan dibutuhkan untuk memperolah sejumlah kombinasi dari produk dan pelayanan. Sementara menurut Philip Kotler, harga yaitu salah satu unsur dalam komponen bauran pemasaran yang mampu menghasilkan pendapatan dari penjualan.

Ada beberapa faktor yang bisa dipengaruhi kepekaan pembeli dari harga:

1. Keunikan, semakin unik produk, akan semakin berkuranglah kepekaan pembeli terhadap harga.

2. Kesadaran adanya pengganti, semakin rendah kesadaran seorang pembeli dengan adanya barnag pengganti, semakin berkurang kepekaan mereka terhadap harga.

3. Kesulitan membandingkan, jika pembali semakin sulit membandingkan mutu produk pengganti, maka akan semakin berkuranglah kepekaannya sama harga. 
4. Mutu harga, jika produk dianggap lebih bermutu maka akan berkurang kepekaan pembeli, karena lebih bergengsi dan lebih eksklusif. (Philip Kotler dan Kevin Lane Keller, 1993:126)

\section{c. Distribusi}

Pendistribusian suatu barang merupakan saluran yang digunakan produsen untuk menyalurkan barang tersebut dari produsen sampai ke konsumen.

Faktor - faktor yang mempengaruhi pemilihan saluran distribusi menurut Kotler adalah :
a. Pertimbangan pasar.
b. Pertimbangan barang.
c. Pertimbangan perusahaan.
d. Pertimbangan perantara.

\section{d. Promosi}

Promosi adalah segala jenis kegiatan pemasaran yang bertujuan untuk meningkatkan permintaan. Menurut Philip Kotler adalah unsur dalam bauran pemasaran perusahaan yang digunakan untuk memberitahukan, mengajak dan mengingatkan tentang produk perusahaan.

Ada 5 metode untuk menjalankan promosi,

a. Penjualan langsung (personal selling), yaitu penyajian suatu produk terhadap konsumen akhir yang dilakukan oleh tenaga penjual perusahaan yang representative.

b. Periklanan (advertising), yaitu bentuk penyajian bukan oleh orang pribadi, yang mengunakan pembayaran oleh sponsor tertentu.

c. Promosi penjualan (sales promotion), yaitu perencanaan untuk membantu atau melengkapi koordinasi periklanan dan penjualan pribadi.

d. Publisitas (publicity), yaitu seperti periklanan yang dijalankan dengan komunikasi untuk menarik permintaan.

e. Hubungan masyarakat (public relation), yaitu merupakan usaha terencana oleh suatu organisasi untuk mempengaruhi sikap atau golongan. (H. Djaslim Saladin ,1994 : 136) 


\section{Etika Bisnis Islam}

Pada dasarnya etika (akhlak) yaitu "perbuatan baik dan buruk manusia." Yang membedakan antara keduanya terletak pada sumbernya. Etika menurut pandangan filsafat bersumber dari akal pikiran semata, sedangkan etika yang juga biasa disebut akhlak dalam Islam bersumber dari syari'at atau agama. Dengan demikian nilai baik maupun buruk dalam etika Islam akan selalu merujuk pada ajaran Alquran dan sunnah rasul. (Abu Hapsin, 2017 : 14)

Alquran memerintahkan umat manusia di bumi ini untuk mencari karunia Allah, karunia tersebut bisa berasal dari salah satu jalan yaitu jual beli (berbisnis). Dijelaskan dalam Alquran surat Al Jumuah ayat 10:

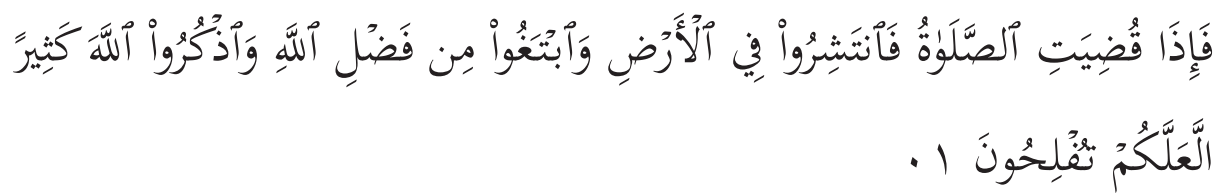

Artinya: Apabila telah ditunaikan shalat, Maka bertebaranlah kamu di muka bumi; dan carilah karunia Allah dan ingatlah Allah banyak-banyak supaya kamu beruntung. (QS. Al Jumuah : 10)

Aayat di atas sudah jelas, Allah memerintahkan manusia untuk mencari karunia-Nya di bumi. Dengan jalan yang baik dan dirindhai oleh Allah. Dalam kaitannya dengan bisnis, ayat ini memerintahkan untuk para pelaku bisnis agar tetap berpegang pada etika atau landasan islam dalam melakukan bisnis, tidak melupakan kewajiban beribadah seperti halnya sholat. Tidak hanya memikirkan dunia tetapi juga memikirkan Allah dan akhirat.

Menurut Yusuf Qardhawi, untuk mengetahu perbedaan islam dengan materialisme yaitu jikalau islam tidak pernah memisahkan ekonomi dengan etika, juga tidak memisahkan ilmu dengan akhlak. Pada konsep islam membebaskan untuk mencari keuntungan sebesar-besarnya namun tetap terikat dengan iman dan etika sehingga tidak bebas mutlak dalam meninvestsikan modal ataupun harta bendanya. (Yusuf Qardhawi, 1997 : 51) 
Etika sebagai arahan dalam suatu masyarakat yang akan mendapatkan bimbingan dan mengingatkan karyawannya kepada suatu tindakan yang terpuji yang harus dipatuhi dan dijalankan. Dan etika dalam bisnis juga harus disepakati oleh orang-orang yang berada dalam lingkaran bisnis serta kelompok yang tekait.

Quraish Shihab, menjelaskan bahwa pada dasarnya bisnis adalah menciptakan keharmonisan hubungan, keharmonisan itu bisa ditunjukkan dengan mencatatkan hutang, seberapa kecil hutang itu jangan lupa untuk menuliskannya, selain itu, tidak melakukan sogok-menyogok karena itu merupakan cara yang batil dan tidak dibenarkan dalam Alquran. Monopoli juga tidak dibenarkan dalam praktik bisnis yang islami.

Kejelasan tentang waktu dan jenis transaksi mutlak dilakukan. Dari sinilah lahir larangan bagi pelaku bisnis untuk melakukan gharar, yaitu bertransaksi menyangkut sesuatu yang tidak jelas kualifikasinya atau waktu penerimaaanya. (M. Quraish Shihab, 2000 : 328)

Etika Bisnis yang dijelaskan Alquran sebagaimana ditulis Quraish Shihab, bahwa berbisnis itu harus jujur, ramah dan toleran, tidak memaksa dan tidak bersumpah dalam melakukan bisnis. (M. Quraish Shihab, 2000 : 329)

Etika Bisnis Islam pada dasarnya adalah sebagaimana yang dilakukan Nabi Muhammad ketika melakukan kegiatan berbisnis. Dalam melakukan transaksi perdagangan (jual-beli) Muhammad melakukan etika seperti berikut ini.

1) Jujur

2) Mencintai pelangan seperti mencintai diri sendiri

3) Menaruh harga yang masuk akal

4) Menepati janji

5) Amanah

6) Toleran

7) Memperlakukan mitra bisnis dengan baik 
Implementasi dari rasa cinta juga dengan memperlakukan mitra bisnis dengan baik,. Mitra bisnis ini salah satunya adalah karyawan. Pelaku bisnis berkewajiban memperlakukan karyawan/ mitra kerjanya dengan baik dan manusiawi. Salah satunya memberikan upahnya sebelum keringatnya kering. Dalam artinya memberikan upah ke karyawan tidak boleh ditunda-tunda, jika waktunya tiba untuk membayarkan gaji/ upah, segerakan untuk membayar gaji/ upah tersebut.

Sedangkan murut Imaddudin seperti dikutip Darmawati dalam Etika Bisnis Dalam Perspektif Islam lima dasar prinsip dalam Etika Bisnis Islam yang bisa dilakukan, antara lain kejujuran (truth, goodness, honesty), keseimbangan (equilibrium), kesatuan (unity), taggungjawab (responsibility), kehendak bebas (free will), kebenaran, dan kebajikan,.

Bagi para pelaku bisnis, sasaran kode etik islam yang perlu dipahami, yaitu menjadikan kaidah islam yang mengatur, mengembangkan dan memperlihatkan metode bisnis yang disesuaikan dengan kerangka agama.

Tanggungjawab para pelaku bisnis dan dalam memberikan penilaian di depan mereka sendiri baru kedepan komunitas bisnis, masyarakat dan terpenting adalah kepada Allah. Dr. Husein Shahatah dan Dr. Siddiq Muhammad al Amin ad Dharir, 2005:34).

Ketika etika bisnis sudah diterapkan dengan baik dan benar sesuai ajaran agama, maka perlu diingat pula bahwa ada aturan dalam berbisnis yang tidak dilakukan atau dilarang, (M. Suyanto, 2008 : 199) antara lain, yaitu, riba, melakukan penipuan, mengambil keuntungan secara batil, curang dan merugikan orang lain, penipuan, monopoli, melakukan sumpah palsu, berkhianat dan melimpahkan bisnis kepada yang belum mampu.

\section{Keputusan Menjadi Nasabah}

Keputusan atau pengambilan keputusan menjadi nasabah merupakan langkah yang dilakukan secara langsung untuk mempergunakan tawaran jasa ada barang pada suatu jenis transaksi bank.

Menurut Philips Kotler dan Amstrong proses pengambilan keputusan itu terdapat 5 tahap yang dilalui. Pertama, yaitu dengan pengenalan akan kebutuhan masyarakat/konsumen atau nasabah. Pada tahap ini nasabah 
merasakan adanya perbedaan antara keadaan nyata dan sejumlah keadaan sedang dicari atau diinginkan. (Philips Kotler dan Gary Armstrong, 2007 : 224).

Keputusan nasabah adalah tahap dimana seorang konsumen (nasabah) memiliki pilihan dan menjatuhkan pilihan keputusan pembelian. (Eko Yuliawan, 2011 : 22) Perilaku konsumen adalah sikap yang diperlihatkan konsumen dalam pencariannya memilih produk, menggunakan, membeli, mengevaluasi, dan membuang produk, jasa dan ide yang mereka kira dapat memenuhi kebutuhan mereka.

\section{Kepuasan Kinerja}

Pada industri layanan bank mengandalkan upaya terbentuknya kepuasan nasabah dengan cara pertama, service profit cycle artinya memberikan pelayanan yang akan memberikan kepuasan nasabah untuk menghasilkan loyalitas sehingga bank akan mendapatkan keuntungan. (Ali Hasan, 2010 : 94)

Kedua, service leverage yaitu memberikan pelayanan yang lebih besar dibandingkan dengan nilai yang digunakan nasabah untuk memperolehnya, karena nasabah mempunyai perhatian kusus membuat nasabah mendorong tumbuhnya loyalitas.

Ketiga, service ability, tingkat kemampuan pelayanan, kecepatan dan kemudahan dalam mendapatkan layanan. Dengan strategi mempertahankan pelanggan, artinya mampu mengelola dan merawat tingkat kepuasan konsumen mengiklankan kualitas, merencanakan ulang produk dan layanan khusus konsumen agar bisa mendapatkan manfaat. Menyederhanakan proses pembelian dan meningkatkan daya tarik produk yang membuat konsumen tidak beralih ke perusahaan lain. (Sudaryono, 2017: 284)

\section{METODE PENELITIAN}

Penelitian ini menggunakan pendekatan kuantitatif, yang merupakan penelitian kausalitas, yang mana di dalamnya terdapat hubungan antara dua variabel atau lebih. Hubungan dalam penelitian ini merupakan hubungan kausal yaitu sebab akibat, diamana ada variabel eksogen (bebas) yaitu variabel yang mempengaruhi variabel endogen (terikat) atau variabel yang dipengaruhi. Populasinya adalah 
masyarakat Kota Semarang yang menjadi nasabah bank syariah (BRI Syariah, Bank Muamalat dan Bank Jateng Syariah) di Kota Semarang yang tidak diketahui secara pasti jumlahnya. Data yang digunakan adalah data primer yang diperoleh langsung dari nasabah menggunakan kuesioner dengan 100 responden yang terdiri dari masing-masing obyek penelitian.

Sampel adalah bagian dari jumlah dan karakteristik yang dimiliki populasi. Jumlah sampel yang diambil dalam penelitian ini sebanyak 100 orang yang diambil secara simple random sampling dan insidental sampling

Dengan menggunakan perhitungan di atas, maka didapatkan jumlah sampel yang akan diteliti adalah sebesar 100 responden/nasabah. Ibnu Widiyanto, 2008: 65).

Teknik analisis data menggunakan pendekatan kuantitatif, dimana hasil dari kuesioner tersebut dikumpulkan dalam suatu tabel untuk dianalisis secara kuantitatif. Alat yang digunakan dalam penelitian ini adalah analisis jalur (path analysis) dengan menggunakan sofware WarpPLS . 5.0.

Metode analisis data penelitian ini menggunakan software WarpPLS versi 5.0 yang diolah dengan perangkat komputer. PLS (Partial Least Square) adalah Analisis persamaan struktural (structural equation model, $P L S$ ) berbasis varian yang secara simultan dapat melakukan pengujian model pengukuran sekaligus pengujian model struktural. Model pengukuran digunakan untuk uji validitas dan reliabilitas, sedangkan model struktural digunakan untuk uji kausalitas (pengujian hipotesis dengan model prediksi).

\section{PEMBAHASAN}

\section{1) Analisis Statistik Deskriptif}

Analisis statistik deskriptif dilakukan agar bisa memberikan gambaran terhadap variabel-variabel yang digunakan dalam penelitian ini. Deskripsi data yang ditampilkan meliputi jumlah responden, Max, Min, Mean, dan Standard Deviation. Di bawah ini adalah tabel yang menampilkan data jumlah responden, Max, Min, Mean, dan Standard Deviation. 
Tabel 4.11

Deskriptif Statistik

\begin{tabular}{|c|c|c|c|c|c|c|}
\hline Variabel & Indikator & $\mathbf{N}$ & Max & Min & Mean & $\begin{array}{c}\text { Std. } \\
\text { Devision }\end{array}$ \\
\hline \multirow{4}{*}{ Marketing Mix } & Produk & 100 & 5 & 1,75 & 4,0275 & 0,70 \\
\hline & Harga & 100 & 5 & 2,4 & 4,08 & 0,65 \\
\hline & Promosi & 100 & 5 & 1,8 & 3,89 & 0,73 \\
\hline & Tempat & 100 & 5 & 2 & 3,9325 & 0,78 \\
\hline \multirow{4}{*}{ Etika Bisnis Islam } & Jujur & 100 & 5 & 2 & 4,256 & 0,63 \\
\hline & Ramah & 100 & 5 & 2,5 & 4,425 & 0,66 \\
\hline & Tepat Janji & 100 & 5 & 2 & 4,126 & 0,75 \\
\hline & Adil & 100 & 5 & 3 & 4,33 & 0,60 \\
\hline $\begin{array}{l}\text { Keputusan Menjadi } \\
\text { Nasabah }\end{array}$ & $\begin{array}{l}\text { Melakukan } \\
\text { Penyimpanan / } \\
\text { Peminjaman }\end{array}$ & 100 & 5 & 2 & 4,33 & 0,87 \\
\hline \multirow{2}{*}{ Loyalitas } & Transaksi Berulang & 100 & 5 & 2 & 4,07 & 0,90 \\
\hline & Merekomendasi & 100 & 5 & 2 & 3,91 & 0,93 \\
\hline
\end{tabular}

Sumber data: Kuesioner diolah 2020

Hasil analisis statistik deskriptif yang ditunjukkan tabel 4.11 menunjukkan bahwa Marketing Mix dengan 4 indikator, variabel Etika Bisnis Islam dengan 4 indikator, variabel Keputusan Menjadi Nasabah dengan 1 indikator dan variabel Loyalitas menjadi Nasabah 2 indikator memiliki nilai maksimum, minimum, rata-rata dan standard deviation seperti tabel di atas dengan jumlah data sebanyak 100 responden.

\section{2) Hasil Analisis Statistik Inferensial}

\section{Analsis Model Pengukuran (Outer Model) \\ a. Indicator Reliability}

Evaluasi model pengukuran (outer model) dengan konstruk berbentuk formatif, dapat dilakukan dengan melihat signifikan weight nya. Jika nilai 
weight yang dihasilkan signifikan $(\mathrm{P}<0.05)$, maka indikator atau item tersebut memenuhi kriteria indicator reliability.

b. Collineariry Collinearity diperlukan dalam model ini karena konstruk formatif merupakan hubungan regresi berganda dari indikator ke konstruk. Cara yang umum digunakan untuk menguji Collinearity dengan melihat ukuran variance inflation factor (VIF) dan lawannya Tolerance. Model dinyatakan baik jika memiliki nilai VIF $<5$ atau $<3.3$.

Tabel di bawah ini merupakan hasil estimasi perhitungan untuk hipotesis 1 dan 2 dengan menggunakan PLS sebagai berikut:

Tabel 4.12

Nilai Outer Konstruk Marketing Mix, Etika Bisnis Islam, Keputusan Menjadi Nasabah dan Loyalitas Nasabah

\begin{tabular}{|c|c|c|c|c|c|}
\hline Konstruk & Indikator & (P-Value) & VIF & Weight & Keterangan \\
\hline \multirow{4}{*}{ Marketing Mix } & Produk & 0,001 & 3,771 & 1 & $\begin{array}{l}\text { Memenuhi Indicator } \\
\text { Reliability dan Collinearity }\end{array}$ \\
\hline & Harga & 0,002 & 3,095 & 1 & $\begin{array}{l}\text { Memenuhi Indicator } \\
\text { Reliability dan Collinearity }\end{array}$ \\
\hline & Promosi & 0,001 & 3,050 & 1 & $\begin{array}{l}\text { Memenuhi Indicator } \\
\text { Reliability dan Collinearity }\end{array}$ \\
\hline & Tempat & 0,002 & 2,425 & 1 & $\begin{array}{l}\text { Memenuhi Indicator } \\
\text { Reliability dan Collinearity }\end{array}$ \\
\hline \multirow{4}{*}{$\begin{array}{l}\text { Etika Bisnis } \\
\text { Islam }\end{array}$} & Jujur & $<0,001$ & 2,404 & 1 & $\begin{array}{l}\text { Memenuhi Indicator } \\
\text { Reliability dan Collinearity }\end{array}$ \\
\hline & Ramah & 0,001 & 1,940 & 1 & $\begin{array}{l}\text { Memenuhi Indicator } \\
\text { Reliability dan Collinearity }\end{array}$ \\
\hline & Menepati Janji & $<0,001$ & 2,653 & 1 & $\begin{array}{l}\text { Memenuhi Indicator } \\
\text { Reliability dan Collinearity }\end{array}$ \\
\hline & Adil & $<0,001$ & 2,067 & 1 & $\begin{array}{l}\text { Memenuhi Indicator } \\
\text { Reliability dan Collinearity }\end{array}$ \\
\hline $\begin{array}{l}\text { Keputusan } \\
\text { Menjadi } \\
\text { Nasabah }\end{array}$ & $\begin{array}{l}\text { Melakukan } \\
\text { Penyimpanan / } \\
\text { Peminjaman }\end{array}$ & $<0,001$ & 0,000 & 1 & $\begin{array}{l}\text { Memenuhi Indicator } \\
\text { Reliability dan Collinearity }\end{array}$ \\
\hline \multirow{2}{*}{$\begin{array}{l}\text { Loyalitas } \\
\text { Nasabah }\end{array}$} & $\begin{array}{l}\text { Transaksi } \\
\text { Berulang }\end{array}$ & $<0,001$ & 1,517 & 1 & $\begin{array}{l}\text { Memenuhi Indicator } \\
\text { Reliability dan Collinearity }\end{array}$ \\
\hline & Merekomendasi & $<0,001$ & 1,517 & 1 & $\begin{array}{l}\text { Memenuhi Indicator } \\
\text { Reliability dan Collinearity }\end{array}$ \\
\hline
\end{tabular}

Sumber : OutputWarp PLS 5.0, data diolah 2020 
Pada tabel 4.12 di atas menunjukkan hasil uji Indicator Reliability dan Collinearity. Indikator Variabel Marketing Mix, Etika Bisnis Islam, Keputusan Menjadi Nasabah dan Loyaliltas Nasabah dengan nilai P-value $<0.05$ dan nilai VIF di bawah 5, data tersebut menunjukkan kalau model terhindar dari masalah Reliability dan Collinearity.

\section{Analisis Model Struktural (Inner Model)}

Evaluasi model struktural (inner model) meliputi Adjusted R2, Q2 Predictive relevance, effect size, APC, ARS, AARS uji kecocokan model (model fit), dan path coefficient. Pada tabel 4.13 berikut ini menunjukkan hasil untuk model struktural (Inner Model) sebagai berikut:

Tabel 4.13

General SEM Analysis Result

\begin{tabular}{|c|c|c|}
\hline & Indeks & Keterangan \\
\hline \multirow{2}{*}{ R Square } & $\mathrm{KMN} \circledast 0,363$ & $\mathrm{KMN}=$ Moderate $(\leq 0,45$ \\
\hline & LOYAL $® 0,704$ & LOYAL $=$ Kuat $(\leq 0,70$ \\
\hline \multirow{2}{*}{ Adjusted $\mathrm{R}^{2}$} & $\mathrm{KMN} \circledast 0,350$ & $\mathrm{KMN}=$ Moderate $(\leq 0,45)$ \\
\hline & LOYAL $® 0,695$ & LOYAL $=$ Kuat $(\leq 0,70)$ \\
\hline \multirow{2}{*}{$\begin{array}{l}\text { Q2 predictive } \\
\text { relevance }\end{array}$} & $\mathrm{KMN} \circledast 0,362$ & \multirow{2}{*}{$\begin{array}{l}\text { Model Memiliki Predictive } \\
\text { Relevancce }\left(Q^{2}>0\right)\end{array}$} \\
\hline & LOYAL $® ~ 0,667$ & \\
\hline \multirow{8}{*}{ Effect size } & & $\geq 0.02$ (kecil), \\
\hline & MMIX $®$ KMN 0,228 & $\geq 0.15$ (sedang), \\
\hline & EBIS $®$ KMN 0,134 & $\geq 0.35$ (besar) \\
\hline & \multirow{2}{*}{ MMIX $®$ LOYAL 0,358 } & MMIX $®$ KMN = Sedang \\
\hline & & EBIS $®$ KMN = Sedang \\
\hline & EBIS ® LOYAL 0,019 & MMIX $®$ LOYAL = Besar \\
\hline & \multirow[t]{2}{*}{ KMN $®$ LOYAL 0,326 } & EBIS $®$ LOYAL = Sedang \\
\hline & & KMN $\AA$ LOYAL = Besar \\
\hline
\end{tabular}




\begin{tabular}{lll}
\hline $\begin{array}{l}\text { APC, ARS dan } \\
\text { AARS }\end{array}$ & $\begin{array}{l}\mathrm{P}<0,001, \mathrm{P}<0,001 \text { dan } \\
\mathrm{P}<0,001\end{array}$ & DITERIMA \\
\hline AVIF dan AFVIF & AVIF $® 2,212$ & DAPAT DITERIMA $(\leq 3,3)$ \\
& AFVIF $\AA 2,832$ & \\
\hline $\begin{array}{l}\text { GoodnesS } \\
\text { Tenenhaus }\end{array}$ & 0,0661 & BESAR \\
\hline SPR & 1,000 & DITERIMA \\
\hline RSCR & 1,000 & DITERIMA \\
\hline NLBCDR & 1,000 & DITERIMA \\
\hline
\end{tabular}

Sumber : OutputWarp PLS 5.0, data diolah 2020

a. $\left(\mathrm{R}^{2}\right) \mathrm{R}$-Square. Besarnya pengaruh Marketing Mix (MMIX) dan Etika Bisnis Islam (EBIS) terhadap Keputusan Menjadi Nasabah (KMN), Marketing Mix (MMIX), Etika Bisnis Islam (EBIS) dan Keputusan Menjadi Nasabah (KMN) terhadap Loyalitas Nasabah (Loyal) bisa dilihat pada nilai $R$-Square Coefficientnya yaitu sebesar 0,36 dan 0,70 yang artinya bahwa $36 \%$ gabungan variabel penelitian mampu mempengaruhi keputusan menjadi nasabah, sedangkan 64\% dipengaruhi variabel lain di luar faktor pada penelitian, dan sebesar 70 \% Loyalitas Nasabah dipengaruhi oleh gabungan variabel yang dipilih, sedangkan 30\% dipengaruhi faktor lain di luar variabel penelitian.

b. Q2 predictive relevance. Pada model penelitian ini nilai Q2 untuk Keputusan Menjadi Nasabah (KMN) sebesar 0,362 artinya besarnya persentase pengaruh yang bisa dijelaskan model adalah sebesar 36,2 $\%$ sedangkan 63,8 \% selebihnya dipengaruhi faktor lain di luar model penelitian. Dan Q2 untuk Loyalitas Nasabah (Loyal) sebesar 0,667 artinya besarnya persentase pengaruh yang bisa dijelaskan model adalah sebesar $66,7 \%$ sedangkan $33,3 \%$ selebihnya dipengaruhi faktor lain di luar model penelitian ini.

c. $A P C, A R S$, dan $A A R S . A P C, A R S$ dan $A A R S$ digunakan untuk mengukur ratarata nilai path koefisien, $R$-square dan Adjusted $R$-square yang dihasilkan dalam model. Nilai $A P C, A R S$, dan $A A R S$ sebesar $<0,001,<0,001$ dan $<0,001$, nilai ini $<0,05$ artinya dapat disimpulkan bahwa model fit atau layak. 
d. AVIF dan AFVIF. AVIF dan AFVIF merupakan dua ukuran fit model yang digunakan untuk menguji masalah collinearity. Hasil menunjukkan nilai AVIF sebesar 2,212 dan AFVIF sebesar 2,832, artinya nilai ini $<3,3$ sehingga model tidak bermasalah dengan collinearity.

e. Goodness of Fit (GoF). GoF adalah akar kuadrat average communality dikalikan dengan ARS nilai GoF $\geq 0.10, \geq 0.25$ dan $\geq 0.36$ (menunjukkan kecil, menengah dan besar). Hasil penelitian menunjukkan nilai Goodness Tenenhaus (GoF) sebesar 0,0661 yang berarti Goodness of Fit model besar karena $>0,15$.

\section{Pengujian Hipotesis}

Pengujian hipotesis bisa digunakan untuk menjelentrehakn arah hubungan antara variabel independen dan variabel dependennya. Pengujian dilakukan dengan cara analisis jalur (path analysis) atas model yang sudah dibuat, hasil untuk path coefficients analysis terangkum dalam tabel di bawah ini.

Tabel 4.14

Hasil Analisis Full Model

\begin{tabular}{|c|c|c|c|c|}
\hline \multicolumn{4}{|c|}{ Path Coefficients } & Kesimpulan \\
\hline $\begin{array}{c}\text { Hubungan antar } \\
\text { Variabel }\end{array}$ & Estimate & P-Value & SE & \\
\hline MMIX ® KMN & 0,395 & $<0,001$ & 0,090 & Diterima \\
\hline EBIS $®$ KMN & 0,249 & 0,004 & 0,093 & Diterima \\
\hline MMIX $®$ LOYAL & 0,491 & $<0,001$ & 0,088 & Diterima \\
\hline EBIS $®$ LOYAL & 0,033 & 0,371 & 0,099 & Ditolak \\
\hline KMN @ LOYAL & 0,452 & $<0,001$ & 0,088 & Diterima \\
\hline \multicolumn{5}{|c|}{ Signifikansi (two-tailed) $P$ value $=0.05$} \\
\hline
\end{tabular}

\section{SIMPULAN}

Berdasarkan tujuan penelitian yang dituliskan di atas, dapat disimpulkan bahwa marketing mix berpengaruh positef dan signifikan terhadap keputusan menjadi nasabah. Etika bisnis islam yang juga menjadi salah sati indicator penelitian ini juga mempunyai pengaruh yang positif dan signifikan terhadap keputusan menjadi nasabah. 
Marketing mix juga berpengaruh positif dan signifikan terhadap loyalitas nasabah. Namun etika bisnis islam rupanya tidak berpengaruh secara signifikan terhadap loyalitas nasabah. Keputusan menjadi nasabah mempunyai pengaruh yang positif dan signifikan terhadap loyalitas nasabah.

Keputusan menjadi nasabah mampu memediasi hubungan antara marketing mix dengan loyalitas nasabah. keputusan menjadi nasabah mampu memediasi hubungan antara etika bisnis islam dengan loyalitas nasabah.

\section{DAFTAR PUSTAKA}

Abu Hapsin,Ph.D. (2017). Melampaui Formalisme Fiqh, Kontruksi Fiqh Etik Al-Ghazali, Semarang: eLSA Press

Basu Swastha DH. (1994). Asas-asas Marketing, Cetakan Ketiga, Yogyakarta: Liberty.

Dr. Husein Shahatah dan Dr. Siddiq Muhammad al Amin ad Dharir, Penerjemah Saptono Budi Satryo dan Fauziah. 2005).Transaksi dan Etika Bisnis dalam Islam, Jakarta: Visi Insani Publishing.

Dr. Sudaryono. (2017). Pengantar Manajemen Teori dan Kasus, Yogyakarta: CAPS (Center for Academic Publishing Servise).

Drs. Danang Sunyoto, SH, S.E, MM dan Wika Harisa Putri, SE,M.Sc, M.E.I. (2016). Etika Bisnis. Yogyakarta: CAPS (Center for Academic Publishing Servise).

Eko Yuliawan. (2011). Pengaruh Pengetahuan Konsumen Mengenai Perbankan Syariah Terhadap Keputusan Menjadi Nasabah Pada PT. Bank Syariah Cabang Bandung. Wira Ekonomi Mikroskil, vol. 1, No. 01

H. Djaslim Saladin, SE. (1994). Dasar-dasar Manajemen Pemasaran, Bandung: CV. Mandar Maju.

https://sp2010.bps.go.id/index.php/site/tabel?tid=321

Ibnu Widiyanto. (2008). Pointers Metodologi Penelitian Penerbit. Semarang: CV Dikalia.

Johan Arifin. (2009). Etika Bisnis Islami, Semarang; Rasail.

K. Bertens. (1994). Etika; Jakarta: Gramedia.

Khafiatul Hasanah. (2016).Pengaruh Karakteristik Marketing Syariah terhadap Keputusan Menjadi Nasabah BMT UGT Sidogiri Cabang Pamekasan, Iqtishadia,. 
M. Quraish Shihab (2000). Secercah Cahaya Ilahi Hidup Bersama Alquran, Bandung: Mizan.

M. Suyanto. (2008). Muhammad Bussiness Strategy \& Ethics, Yogykarta: Andi Publisher.

Philip Kotler dan Kevin Lane Keller. (1993). Manajemen Pemasaran, jilid 2, Jakarta: Penerbit Erlangga.

Philips Kotler dan Gary Armstrong. (2007). Dasar-Dasar Pemasaran, Jakarta: Indeks Gramedia.

Rauly Sijabat. (2017). Penguatan Kinerja Pemasaran Melalui Pengembangan Inovasi dan Kreativitas Program Kerja pada Wirausaha Muda di Semarang, Jurnal Sains Pemasaran Indonesia, Volume XVI, No. 1.

Statistik Perbankan Syariah Tahun 2017, www.ojk.go.id

Teuku Meldi Kesuma. (2012). Prinsip dan Kriteria Periklanan dari Persepktif Islam, Share, Volume 1 No 1 Januari-Juni.

Yusuf Qardhawi. (1997). Norma dan Etika Ekonomi Islam, Jakarta: Gema Insani Press. 
